\title{
Positive association of residual kidney function with hemoglobin level in patients on peritoneal dialysis independent of endogenous erythropoietin concentration
}

\author{
Kazuhiko Tsuruya ${ }^{1,2^{*}+}$, Kumiko Torisu $^{2+}$, Hisako Yoshida ${ }^{1,3}$, Shunsuke Yamada ${ }^{2}$, Shigeru Tanaka ${ }^{2}$, \\ Akihiro Tsuchimoto ${ }^{2}$, Masahiro Eriguchi², Kiichiro Fujisaki ${ }^{2}$, Kosuke Masutani ${ }^{2}$ and Takanari Kitazono ${ }^{2}$
}

\begin{abstract}
Background: How residual kidney function (RKF) functions in the prevention of anemia in peritoneal dialysis (PD) patients is unclear. In this study, we investigated the association between RKF and hemoglobin ( $\mathrm{Hb}$ ) level.

Methods: We performed a cross-sectional analysis of the association between RKF, defined as the mean renal creatinine and urea clearance ( $\mathrm{rCUC}$ ), and the $\mathrm{Hb}$ level in $50 \mathrm{PD}$ patients registered retrospectively. The independent variable was mean rCUC as continuous or categorical variable by tertile, and the dependent variable was Hb level as continuous or dichotomous variable using $\mathrm{Hb}$ cutoff of $10 \mathrm{~g} / \mathrm{dL}$. We conducted a multivariable regression analysis and calculated the c-statistic for $\mathrm{Hb}$ level $<10 \mathrm{~g} / \mathrm{dL}$ using a receiver operating characteristic curve.

Results: In multivariable regression analysis, mean rCUC was significantly associated with Hb level independent of dose of erythropoiesis-stimulating agent (ESA) and endogenous erythropoietin (eEPO) concentration. Multivariable adjusted least square means of the $\mathrm{Hb}$ level were higher with increase in the mean rCUC tertile. The c-statistic ( $95 \%$ confidential interval) for a $\mathrm{Hb}$ level $<10 \mathrm{~g} / \mathrm{dL}$ was significantly greater in the model with mean $\mathrm{rCUC}$ than without [0.931 (0.789-0.980) vs. $0.856(0.697-0.939), P=0.044]$.
\end{abstract}

Conclusion: A decline in RKF is associated with anemia in PD patients independent of ESA dose and eEPO concentration.

Trial registration: UMIN000018902

Keywords: Anemia, Creatinine clearance, Erythropoietin, Hemoglobin, Kt/N, Residual kidney function

\section{Background}

The introduction of erythropoiesis-stimulating agent (ESA) to clinical settings for renal anemia has allowed the easy management of anemia in patients with chronic kidney disease (CKD). Anemia control is considered important for the prediction of mortality and increase in quality of life in CKD patients. However, recent studies

\footnotetext{
*Correspondence: tsuruya@intmed2.med.kyushu-u.ac.jp

${ }^{\dagger}$ Equal contributors

'Department of Integrated Therapy for Chronic Kidney Disease, Graduate School of Medical Sciences, Kyushu University, 3-1-1 Maidashi, Higashi-ku, Fukuoka 812-8582, Japan

${ }^{2}$ Department of Medicine and Clinical Science, Graduate School of Medical Sciences, Kyushu University, Fukuoka, Japan

Full list of author information is available at the end of the article
}

have demonstrated that a large dose of ESA results in a high mortality rate and high incidence of cardiovascular events such as stroke in hemodialysis (HD) patients [1] and those with non-dialysis-dependent CKD [2-4].

The importance of residual kidney function (RKF) in the survival of chronic dialysis patients, especially peritoneal dialysis (PD) patients, was recently reported [5-7]. The "Cardiovascular and Metabolic Clinical Practice Guidelines for Peritoneal Dialysis Patients" by the International Society for Peritoneal Dialysis in 2015 also emphasize the importance of RKF in cardiovascular disease and mortality, recommending that PD patients undergo monitoring of RKF at least once every 6 months [8]. 
Wang and Lai [5] also stressed the importance of RKF in anemia management. Lopez-Menchero et al. [9] reported that in addition to ESA use and iron levels, RKF also correlated significantly with hemoglobin $(\mathrm{Hb})$ levels in PD patients. A recent report by Penne et al. [10] showed a strong relation between RKF and improved anemia control in HD patients. However, how RKF functions and how the endogenous erythropoietin (eEPO) concentration is involved in the prevention of anemia in CKD patients is unclear.

This study investigated the association between RKF and $\mathrm{Hb}$ levels from the perspective of the mechanism by measuring eEPO concentrations in PD patients.

\section{Methods}

\section{Study participants}

The study population comprised 50 patients aged > 18 years who were treated with PD at our hospital between May 2006 and March 2011 and had been followed for at least 6 months. Patients, who did not have any bone marrow disease or cirrhosis of the liver, were registered retrospectively. This study is a subanalysis of our multicenter cohort study (Fukuoka Peritoneal Dialysis Database Study), which was conducted in accordance with the Declaration of Helsinki, was approved by the Institutional Review Boards of Kyushu University Hospital (no. 26-223), and was registered at the University Hospital Medical Information Network (UMIN000018902).

\section{Data collection}

Blood, 24-h urine, and peritoneal dialysate samples were collected from PD patients at least every 6 months to evaluate their dialysis and peritoneal status as well as medical condition [11]. Demographic, clinical, and prescription data at each 6-monthly examination were also recorded based on the guidelines [12]. Venous blood was collected at a regular outpatient clinic visit after fasting, and part of the blood sample was centrifuged at $3000 \times g$ at $4{ }^{\circ} \mathrm{C}$ for $15 \mathrm{~min}$ and stored at $-80{ }^{\circ} \mathrm{C}$ until analysis, except for those used for standard biochemical analyses.

\section{Calculation of $\mathrm{Hb}$ levels and ESA dose}

$\mathrm{Hb}$ levels were assessed based on mean values during the last 3 months of the observation period. Darbepoetin alfa was administered as the ESA in all 50 patients to achieve and maintain a $\mathrm{Hb}$ level of approximately $11 \mathrm{~g} / \mathrm{dL}$ according to the guidelines for anemia in CKD $[13,14]$. The ESA dose was evaluated based on the weekly dose calculated from the total dose during the last 3 months of the observation period.

\section{Measurements of RKF, dialysis adequacy, and peritoneal membrane solute transport}

RKF and dialysis adequacy, which were measured every 6 months in each patient, were calculated as the weekly urea clearance $(\mathrm{Kt} / \mathrm{V})$ and creatinine clearance $(\mathrm{Ccr})$ from 24-h urinary and dialysate clearance, by direct measurement of urea in the urine and each dialysate exchange. The volume of urea distribution in a patient, which is the patient's total body water (TBW), was calculated according to the equations of Hume and Weyers-men: TBW $(\mathrm{L})=0.297$ body weight $(\mathrm{kg})+0.195$ body height $(\mathrm{cm})$ - 14.013; women: TBW (L) $=0.184$ body weight $(\mathrm{kg})+0345$ body height $(\mathrm{cm})-35.27$ [15]. RKF was defined as the mean renal creatinine and urea clearance (rCUC). Peritoneal membrane solute transport was assessed by the peritoneal equilibration test. A standard 4-h dwell period was used (first exchange of the day), with a $2.27 \%$ glucose concentration 2-L volume exchange. The patients used their usual overnight dialysis regimes, and both the overnight and the test drainage volumes were measured. The dialysate-to-plasma ratio of creatinine at the completion of the 4-h dwell period (D/Pcr) was used as the estimate of low molecular weight solute transport.

\section{Measurement of serum eEPO concentration}

Serum eEPO concentration was measured by a chemiluminescent enzyme immunoassay (SRL Inc., Fukuoka, Japan).

\section{Statistical analysis}

Results are expressed as the mean \pm standard deviation, median (interquartile range [IQR]), or number (percentage) as appropriate. The trend among mean rCUC groups was assessed using Cochran-Armitage test for the categorical variables and Jonckheere-Terpstra test for continuous variables. The primary outcome variable was the mean $\mathrm{Hb}$ level during the last 3 months of the observation period. Both univariable and multivariable linear regression analyses were conducted to assess the associations between the $\mathrm{Hb}$ level and the variables. Variables showing a $P$ value of $<0.05$ in the univariable analysis were included in addition to cardiothoracic ratio (CTR), ESA dose, and log-transformed eEPO concentration in the multivariable analyses. To investigate whether the accuracy of predicting $\mathrm{Hb}$ levels improved after addition of the mean rCUC into a basic model (model 1) including the potential risk factors that were significantly associated with $\mathrm{Hb}$ levels in the univariable analysis in addition to CTR, ESA dose, and eEPO concentration, we calculated the c-statistic for $\mathrm{Hb}$ levels $<10 \mathrm{~g} / \mathrm{dL}$ using a receiver operating characteristic curve. For two-tailed tests, $P<0.05$ was considered significant in all analyses. All statistical analyses were conducted using JMP 11.2 software (SAS Institute, Tokyo, Japan) and RStudio Version 0.99.896.

\section{Results}

The characteristics and laboratory data of the 50 patients according to the tertiles of mean rCUC are 
Table 1 Clinical characteristics according to tertiles of mean rCUC

\begin{tabular}{|c|c|c|c|c|c|}
\hline & $\begin{array}{l}\text { Total } \\
(N=50)\end{array}$ & $\begin{array}{l}\mathrm{T} 1(\text { mean rCUC }<11.7 \mathrm{~L} \\
\left.\text { week } 1.73 \mathrm{~m}^{2}\right), n=17\end{array}$ & $\begin{array}{l}\text { T2 (mean rCUC 11.8-29.8 L/ } \\
\text { week/1.73m²), } n=17\end{array}$ & 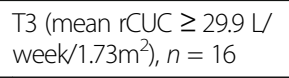 & $\begin{array}{l}P \text { for } \\
\text { trend }\end{array}$ \\
\hline Male sex, n (\%) & $37(74.0)$ & $12(70.6)$ & $11(64.7)$ & $14(87.5)$ & 0.277 \\
\hline Age, years & $54 \pm 14$ & $53 \pm 14$ & $55 \pm 15$ & $55 \pm 15$ & 0.499 \\
\hline Dialysis duration, months & $20.2 \pm 11.6$ & $23.4 \pm 12.3$ & $18.1 \pm 9.7$ & $18.8 \pm 12.5$ & 0.213 \\
\hline \multicolumn{6}{|l|}{ Original disease } \\
\hline $\mathrm{DN}, n(\%)$ & $16(32.0)$ & $7(41.2)$ & $6(35.3)$ & $3(18.8)$ & \multirow[t]{2}{*}{0.167} \\
\hline Non-DN, $n(\%)$ & $34(68.0)$ & $10(58.8)$ & $11(64.7)$ & $13(81.2)$ & \\
\hline \multicolumn{6}{|l|}{ Blood pressure, $\mathrm{mmHg}$} \\
\hline Systolic & $139 \pm 14$ & $141 \pm 11$ & $137 \pm 18$ & $139 \pm 13$ & 0.845 \\
\hline Diastolic & $81 \pm 11$ & $82 \pm 9$ & $78 \pm 16$ & $82 \pm 7$ & 0.581 \\
\hline Daily alcohol consumption, n (\%) & $20(40.0)$ & $5(29.4)$ & $8(47.1)$ & $7(43.8)$ & 0.394 \\
\hline Current smoker, $n(\%)$ & $9(18.0)$ & $3(17.7)$ & $2(11.8)$ & $4(25.0)$ & 0.593 \\
\hline Past histories of CVD, $n(\%)$ & $8(16.0)$ & $2(11.8)$ & $4(23.5)$ & $2(12.5)$ & 0.939 \\
\hline History of peritonitis, $n(\%)$ & $8(16.0)$ & $1(5.9)$ & $3(17.7)$ & $4(25.0)$ & 0.133 \\
\hline Body mass index, $\mathrm{kg} / \mathrm{m}^{2}$ & $22.9 \pm 2.9$ & $22.4 \pm 2.4$ & $22.1 \pm 2.7$ & $24.2 \pm 3.2$ & 0.124 \\
\hline CTR, \% & $48.2 \pm 5.4$ & $49.8 \pm 4.7$ & $48.3 \pm 4.6$ & $46.6 \pm 6.7$ & 0.075 \\
\hline \multicolumn{6}{|l|}{ Dialysis modality } \\
\hline $\mathrm{APD}, n(\%)$ & $22(44.0)$ & $11(64.7)$ & $8(47.1)$ & $9(56.3)$ & \multirow[t]{2}{*}{0.614} \\
\hline CAPD, $n(\%)$ & $28(56.0)$ & $6(35.3)$ & $9(52.9)$ & $7(43.7)$ & \\
\hline Use of icodextrin, $n(\%)$ & $41(82.0)$ & $16(94.1)$ & $13(76.5)$ & $12(75.0)$ & 0.150 \\
\hline Use of HG dialysate, $n(\%)$ & $17(34.0)$ & $11(64.7)$ & $4(23.5)$ & $2(12.5)$ & 0.002 \\
\hline Dose of ESA, $\mu \mathrm{g} /$ week & $34 \pm 18$ & $37 \pm 16$ & $32 \pm 16$ & $31 \pm 23$ & 0.206 \\
\hline Total Kt/N, /week & $1.71 \pm 0.34$ & $1.66 \pm 0.42$ & $1.61 \pm 0.31$ & $1.87 \pm 0.23$ & 0.011 \\
\hline Renal Kt/N, /week & $0.46 \pm 0.37$ & $0.10 \pm 0.11$ & $0.42 \pm 0.18$ & $0.88 \pm 0.27$ & $<0.001$ \\
\hline Peritoneal Kt/N, /week & $1.25 \pm 0.38$ & $1.56 \pm 0.41$ & $1.19 \pm 0.21$ & $0.99 \pm 0.22$ & $<0.001$ \\
\hline Renal Ccr, L/week, /week & $29.2 \pm 26.9$ & $5.1 \pm 4.9$ & $27.4 \pm 8.9$ & $56.8 \pm 27.8$ & $<0.001$ \\
\hline Urine volume, L/day & $0.80 \pm 0.64$ & $0.22 \pm 0.24$ & $0.76 \pm 0.38$ & $1.44 \pm 0.55$ & $<0.001$ \\
\hline Mean rCUC, L/week/1.73m² & $22.7 \pm 19.4$ & $4.2 \pm 4.2$ & $20.5 \pm 6.2$ & $44.5 \pm 16.5$ & $<0.001$ \\
\hline $\mathrm{D} / \mathrm{Pcr}$ & $0.73 \pm 0.16$ & $0.76 \pm 0.16$ & $0.72 \pm 0.17$ & $0.70 \pm 0.16$ & 0.328 \\
\hline \multicolumn{6}{|l|}{ Prescriptions, $n(\%)$} \\
\hline RAS inhibitors & $48(96.0)$ & $17(100.0)$ & $15(88.2)$ & $16(100)$ & 0.972 \\
\hline Calcium channel blockers & $37(74.0)$ & $15(88.2)$ & $10(58.8)$ & $12(75.0)$ & 0.370 \\
\hline$\beta$ blockers & $23(46.0)$ & $11(64.7)$ & $6(35.3)$ & $6(37.5)$ & 0.113 \\
\hline Calcium-containing PBs & $44(88.0)$ & $13(76.5)$ & $16(94.1)$ & $15(93.8)$ & 0.123 \\
\hline Non-calcium containing PBs & $29(58.0)$ & $14(82.4)$ & $6(35.3)$ & $9(56.3)$ & 0.119 \\
\hline Iron preparations & $11(22.5)$ & $7(41.2)$ & $2(11.8)$ & $2(13.3)$ & 0.054 \\
\hline Vitamin D & $27(54.0)$ & $9(52.9)$ & $7(41.2)$ & $11(68.8)$ & 0.375 \\
\hline Cinacalcet hydrochloride & $4(8.0)$ & $1(5.9)$ & $1(5.9)$ & $2(12.5)$ & 0.488 \\
\hline
\end{tabular}

Values are expressed as mean \pm standard deviation or number (percentage) as appropriate

Abbreviations: APD automated peritoneal dialysis, CAPD continuous ambulatory peritoneal dialysis, $C$ cr creatinine clearance, $C T R$ cardiothoracic ratio, CVD cardiovascular disease, $D N$ diabetic nephropathy, D/Pcr dialysate-to-plasma creatinine ratio, ESA erythropoiesis-stimulating agent, $H G$ high-glucose (2.5\%), Kt/V urea clearance, $P B s$ phosphate binders, RAS renin-angiotensin system, $r C U C$ renal creatinine and urea clearance

shown in Tables 1 and 2 , respectively. Total $\mathrm{Kt} / \mathrm{V}$, renal $\mathrm{Kt} / \mathrm{V}$, renal $\mathrm{Ccr}$, urine volume, sodium, and chloride were significantly higher with greater mean rCUC, while the prevalence of diabetic nephropathy
(DN) and high-glucose dialysate users, peritoneal Kt/ $\mathrm{V}$, serum creatinine, brain natriuretic peptide (BNP), and $\beta_{2}$-microglobulin (BMG) were lower with greater mean rCUC. 
Table 2 Laboratory data according to tertiles of mean rCUC

\begin{tabular}{|c|c|c|c|c|c|}
\hline & Total $(N=50)$ & $\begin{array}{l}\text { T1 (mean rCUC < } \\
\left.11.7 \mathrm{~L} / \text { week } / 1.73 \mathrm{~m}^{2}\right), \\
n=17\end{array}$ & $\begin{array}{l}\text { T2 (mean rCUC } \\
\left.11.8-29.8 \mathrm{~L} / \text { week } 1.73 \mathrm{~m}^{2}\right) \text {, } \\
n=17\end{array}$ & $\begin{array}{l}\text { T3 (mean rCUC } \geq \\
\left.29.9 \mathrm{~L} / \text { week } 1.73 \mathrm{~m}^{2}\right) \\
n=16\end{array}$ & $P$ for trend \\
\hline Total protein, g/dL & $6.4 \pm 0.7$ & $6.5 \pm 0.6$ & $6.2 \pm 0.6$ & $6.4 \pm 0.7$ & 0.539 \\
\hline Albumin, $\mathrm{g} / \mathrm{dL}$ & $3.5 \pm 0.4$ & $3.5 \pm 0.4$ & $3.4 \pm 0.5$ & $3.6 \pm 0.4$ & 0.270 \\
\hline Blood urea nitrogen, mg/dL & $65 \pm 13$ & $63 \pm 10$ & $68 \pm 17$ & $67 \pm 12$ & 0.460 \\
\hline Creatinine, mg/dL & $11.5 \pm 3.0$ & $13.1 \pm 3.1$ & $11.1 \pm 2.3$ & $10.1 \pm 3.0$ & 0.003 \\
\hline Uric acid, mg/dL & $6.8 \pm 1.1$ & $6.7 \pm 1.2$ & $6.7 \pm 1.0$ & $6.9 \pm 1.1$ & 0.341 \\
\hline Sodium, mEq/L & $136 \pm 4$ & $134 \pm 3$ & $137 \pm 3$ & $139 \pm 2$ & $<0.001$ \\
\hline Potassium, mEq/L & $4.4 \pm 0.6$ & $4.4 \pm 0.7$ & $4.2 \pm 0.6$ & $4.7 \pm 0.5$ & 0.306 \\
\hline Chloride, $\mathrm{mEq} / \mathrm{L}$ & $98 \pm 5$ & $94 \pm 3$ & $98 \pm 4$ & $102 \pm 4$ & $<0.001$ \\
\hline Calcium, mg/dL & $9.5 \pm 0.4$ & $9.5 \pm 0.4$ & $9.5 \pm 0.5$ & $9.5 \pm 0.4$ & 0.643 \\
\hline Phosphate, mg/dL & $5.4 \pm 1.2$ & $5.4 \pm 1.7$ & $5.3 \pm 0.7$ & $5.4 \pm 1.2$ & 0.894 \\
\hline Glucose, mg/dL & $108 \pm 31$ & $112 \pm 35$ & $105 \pm 26$ & $107 \pm 34$ & 0.408 \\
\hline Total cholesterol, mg/dL & $182 \pm 44$ & $168 \pm 33$ & $195 \pm 58$ & $183 \pm 37$ & 0.355 \\
\hline Triglyceride, mg/dL & $126 \pm 73$ & $126 \pm 84$ & $114 \pm 53$ & $138 \pm 82$ & 0.569 \\
\hline $\mathrm{LDL}-\mathrm{C}, \mathrm{mg} / \mathrm{dL}$ & $96 \pm 27$ & $85 \pm 22$ & $105 \pm 26$ & $100 \pm 30$ & 0.176 \\
\hline $\mathrm{HDL}-\mathrm{C}, \mathrm{mg} / \mathrm{dL}$ & $52 \pm 18$ & $53 \pm 14$ & $53 \pm 22$ & $52 \pm 16$ & 0.794 \\
\hline $\mathrm{Hb}, \mathrm{g} / \mathrm{dL}$ & $10.2 \pm 1.1$ & $9.8 \pm 1.0$ & $10.0 \pm 1.2$ & $10.9 \pm 0.7$ & $<0.001$ \\
\hline C-reactive protein, $\mathrm{mg} / \mathrm{dL}$ & $0.08(0.03-0.13)$ & $0.07(0.04-0.15)$ & $0.08(0.03-0.22)$ & $0.06(0.03-0.11)$ & 0.631 \\
\hline Serum iron, $\mu \mathrm{g} / \mathrm{dL}$ & $87 \pm 26$ & $84 \pm 26$ & $87 \pm 31$ & $88 \pm 22$ & 0.735 \\
\hline $\mathrm{TIBC}, \mu \mathrm{g} / \mathrm{dL}$ & $283 \pm 34$ & $301 \pm 34$ & $268 \pm 37$ & $281 \pm 22$ & 0.074 \\
\hline TSAT, \% & $30.7 \pm 9.3$ & $28.2 \pm 8.8$ & $32.2 \pm 10.3$ & $31.7 \pm 8.7$ & 0.213 \\
\hline Ferritin, ng/mL & $130(80-220)$ & $108(73-205)$ & $216(89-306)$ & $113(59-177)$ & 0.643 \\
\hline Whole PTH, pg/mL & $94(55-151)$ & $89(55-128)$ & $92(37-173)$ & $97(52-163)$ & 0.801 \\
\hline BNP, pg/mL & $86(37-298)$ & $222(67-468)$ & $101(34-433)$ & $47(20-116)$ & 0.023 \\
\hline $\mathrm{eEPO}, \mathrm{U} / \mathrm{mL}$ & $16.0(13.6-25.1)$ & $22.1(13.9-24.9)$ & $17.7(13.9-24.3)$ & $18.6(14.0-23.7)$ & 0.618 \\
\hline $\mathrm{BMG}, \mathrm{mg} / \mathrm{L}$ & $23.2(18.1-28.8)$ & $28.6(26.6-37.3)$ & $22.8(19.9-29.6)$ & $17.6(14.6-18.9)$ & $<0.001$ \\
\hline $\mathrm{HbA} 1 \mathrm{c}, \%$ & $5.4 \pm 0.7$ & $5.3 \pm 0.8$ & $5.5 \pm 0.7$ & $5.5 \pm 0.8$ & 0.128 \\
\hline
\end{tabular}

Values are expressed as mean \pm standard deviation or median (interquartile range) as appropriate

Abbreviations:BMG $\beta_{2}$-microglobulin, BNP brain natriuretic peptide, eEPO endogenous erythropoietin, $H b$ hemoglobin, $H b A 1 c$ hemoglobin A1c, $H D L-C$ high-density lipoprotein cholesterol, LDL-C low-density lipoprotein cholesterol, PTH parathyroid hormone, $r C U C$ renal creatinine and urea clearance, TIBC total iron binding capacity, TSAT transferrin saturation

The mean $\mathrm{Hb}$ levels were higher with greater mean rCUC (Table 2). This trend remained statistically significant [least square mean \pm standard error: $9.7 \pm 0.2$, $10.2 \pm 0.2$, and $10.8 \pm 0.2$ in T1, T2, and T3, respectively; $P$ for trend $=0.002$ ] even after adjustment for model 1 (dialysis duration, current smoking habit, dose of ESA, log-transformed ferritin, log-transformed BNP, logtransformed $\mathrm{eEPO}$, total $\mathrm{Kt} / \mathrm{V}$, and $\mathrm{CTR}$ ) by analysis of covariance (Fig. 1).

Univariable regression analysis revealed that dialysis duration, current smoker, total $\mathrm{Kt} / \mathrm{V}$, renal $\mathrm{Kt} / \mathrm{V}$, renal Ccr, mean rCUC, and urine volume were positively associated and that log-transformed ferritin and log-transformed BNP were negatively associated with $\mathrm{Hb}$ levels. In the multivariable regression analysis, containing model 1 plus mean $\mathrm{rCUC}$, dialysis duration and mean $\mathrm{rCUC}$ remained significant (Table 3). We did not enter renal $\mathrm{Kt} / \mathrm{V}$, renal $\mathrm{Ccr}$, and urine volume in the multivariable model because of their multicollinearity with mean $\mathrm{rCUC}(r=0.919$, 0.980 , and -0.756 ) in the multivariable analysis.

To evaluate the impact of the mean rCUC on the accuracy of assessment, we compared the discriminatory abilities between model 1 (dialysis duration, current smoking habit, dose of ESA, log-transformed ferritin, logtransformed $\mathrm{BNP}$, log-transformed eEPO, total $\mathrm{Kt} / \mathrm{V}$, and CTR) and the following models: model 1 plus mean rCUC, urine volume, renal $\mathrm{Kt} / \mathrm{V}$, renal $\mathrm{Ccr}$, or logtransformed BMG. The c-statistic (95\% confidential interval) for a $\mathrm{Hb}$ level $<10 \mathrm{~g} / \mathrm{dL}$ was significantly greater in model 1 plus mean rCUC than model 1 [0.931 (0.789$0.980)$ vs. 0.856 (0.697-0.939), $P=0.044]$. However, no significant increases in the c-statistic (95\% confidential 

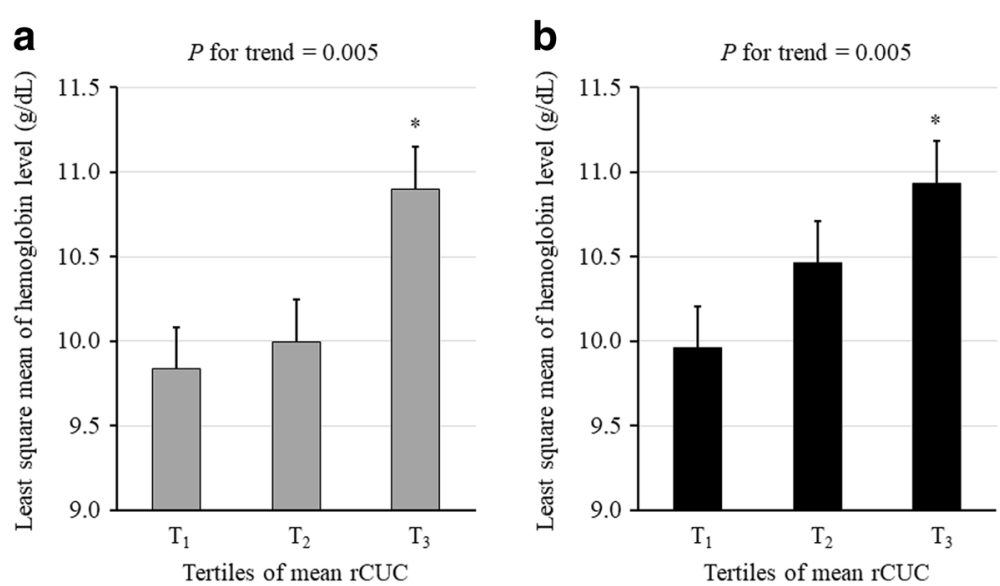

Fig. $1 \mathrm{Hb}$ level according to the tertiles of mean rCUC. Least square means of Hb level according to the tertiles of mean rCUC in the univariable model (a) and the multivariable-adjusted regression model (b). A linear regression model was used to compare the least square mean among the tertile groups. ${ }^{*} P<0.01$ vs. T1. Abbreviations: $\mathrm{Hb}$ hemoglobin, $r C U \mathrm{C}$ renal creatinine and urea clearance, $T$ tertile

interval) were found in model 1 plus urine volume $[0.906$ (0.776-0.964), $P=0.192]$, renal Kt/V [0.924 (0.767-0.978), $P=0.061]$, renal Ccr $[0.929(0.795-0.978), P=0.058]$, or log-transformed BMG [0.880 (0.738-0.950), $P=0.491]$ compared with model 1.

\section{Discussion}

The present study suggests that RKF represents an important correlate of $\mathrm{Hb}$ level in PD patients and that this correlation is independent of ESA dose and eEPO concentration. Therefore, the findings suggest that hematopoiesisinhibiting uremic toxins, which are mainly removed by RKF, but not by PD, are a major cause of anemia in PD patients.

Ifudu et al. [16] reported an independent positive correlation between dialysis dose and hematocrit level when investigating the contribution of hematocrit in $135 \mathrm{HD}$ patients receiving ESA. A comparison of 20 patients whose dialysis dose was increased with 20 patients with similar baseline characteristics whose dialysis dose was unaltered showed that the hematocrit level was significantly increased in the former group after 6 weeks, but remained unchanged in the latter group, demonstrating the importance of dialysis dose on anemia management. In a retrospective study by Matsuo et al. [17], in which 53 patients on PD monotherapy were moved to a combined regimen of HD + PD following a diagnosis of underdialysis and/or overhydration with declining RKF, a significant increase in $\mathrm{Hb}$ levels (from 8.2 to $10.7 \mathrm{~g} / \mathrm{dL}$ ) was found without an increase in ESA dose. The present study of PD monotherapy, however, found no evidence to suggest a significant correlation between dialysis dose (peritoneal $\mathrm{Kt} / \mathrm{V}$ ) and $\mathrm{Hb}$ level. We consider that this was because of the superior solute clearance of HD compared with PD. Evenepoel et al. [18] reported that high-flux HD delivered significantly higher clearance of all retention solutes, especially BMG and p-cresol compared with peritoneal dialysis, although renal clearances, conversely, were significantly higher in patients in PD.

A significant association of total $\mathrm{Kt} / \mathrm{V}$, calculated by the addition of renal $\mathrm{Kt} / \mathrm{V}$ to peritoneal $\mathrm{Kt} / \mathrm{V}$, with $\mathrm{Hb}$ level, was observed in the univariable regression analysis. However, the significant association was diminished in the multivariable regression analysis (Table 3). Furthermore, no association was found between peritoneal $\mathrm{Kt} / \mathrm{V}$ and $\mathrm{Hb}$ level. According to these findings, maintaining RKF, but not an increase in dialysis dose, is important for the control of $\mathrm{Hb}$ levels in $\mathrm{PD}$ patients. Taken together, these findings show that standard PD is insufficient to eliminate factors influencing anemia, suggesting the presence of a hematopoiesis-inhibiting substance that is typically removed and eliminated by RKF, but not by PD.

The mechanism of the association between RKF and $\mathrm{Hb}$ remains to be elucidated. In the present study, logtransformed BMG was closely correlated with mean rCUC $(r=-0.736, P<0.001)$, suggesting the possibility of this factor as an important cause of low RKFassociated anemia. However, a significant association was not observed in the univariable regression analysis (Table 3) and also in the multivariable regression analysis when log-transformed BMG was entered instead of mean rCUC (Additional file 1: Table S1).

However, Pawlak et al. [19] described the contribution of quinolinic acid in the development of anemia in CKD patients. Quinolinic acid is an intermediate of the metabolic pathway responsible for the conversion of tryptophan into nicotinic acid and is an $N$-methyl-D-aspartate (NMDA) receptor agonist with putative neuroexcitatory and neurotoxic properties [20]. Another candidate for the potential contributing factor of anemia is indoxyl sulfate, a representative uremic toxin. Chiang et al. [21] 
Table 3 Univariable and multivariable regression analysis for $\mathrm{Hb}$ levels

\begin{tabular}{|c|c|c|c|c|c|}
\hline & Univariable & & Multivariable & & \\
\hline & $\beta$-coefficient & $P$ & $\beta$-coefficient & Standardized $\beta$ & $P$ \\
\hline Male sex & -0.223 & 0.534 & & & \\
\hline Age, years & 0.005 & 0.658 & & & \\
\hline Primary disease of kidney disease, DN & -0.383 & 0.254 & & & \\
\hline Dialysis duration, months & 0.038 & 0.004 & 0.033 & 0.346 & 0.008 \\
\hline Body mass index, $\mathrm{kg} / \mathrm{m}^{2}$ & -0.020 & 0.713 & & & \\
\hline Systolic blood pressure, mmHg & -0.014 & 0.199 & & & \\
\hline Diastolic blood pressure, $\mathrm{mmHg}$ & 0.007 & 0.605 & & & \\
\hline Daily alcohol consumption & 0.405 & 0.204 & & & \\
\hline Current smoker & 0.927 & 0.020 & 0.240 & 0.170 & 0.211 \\
\hline Past histories of CVD & 0.553 & 0.194 & & & \\
\hline History of peritonitis & -0.134 & 0.756 & & & \\
\hline CTR, \% & -0.032 & 0.277 & 0.037 & 0.181 & 0.280 \\
\hline Dose of ESA, $\mu \mathrm{g} /$ week & -0.002 & 0.823 & 0.001 & 0.010 & 0.943 \\
\hline Dialysis modality, APD & -0.078 & 0.805 & & & \\
\hline Use of icodextrin & 0.319 & 0.435 & & & \\
\hline Use of HG dialysate & 0.258 & 0.437 & & & \\
\hline Total Kt/N, /week & 1.038 & 0.021 & 0.330 & 0.104 & 0.425 \\
\hline Renal Kt $/ N$, /week & 1.400 & $<0.001$ & & & \\
\hline Peritoneal Kt/N, /week & -0.501 & 0.232 & & & \\
\hline Renal Ccr, L/week, /week/1.73m² & 0.017 & 0.003 & & & \\
\hline Mean rCUC, L/week & 0.024 & 0.002 & 0.018 & 0.321 & 0.045 \\
\hline Urine volume, L/day & 0.630 & 0.009 & & & \\
\hline $\mathrm{D} / \mathrm{Pcr}$ & -0.881 & 0.371 & & & \\
\hline Total protein, g/dL & 0.322 & 0.183 & & & \\
\hline Albumin, g/dL & 0.517 & 0.150 & & & \\
\hline Blood urea nitrogen, mg/dL & -0.020 & 0.103 & & & \\
\hline Creatinine, mg/dL & -0.092 & 0.077 & & & \\
\hline Uric acid, mg/dL & 0.123 & 0.393 & & & \\
\hline Sodium, mEq/L & 0.048 & 0.272 & & & \\
\hline Potassium, mEq/L & 0.082 & 0.752 & & & \\
\hline Chloride, $\mathrm{mEq} / \mathrm{L}$ & 0.055 & 0.109 & & & \\
\hline Calcium, mg/dL & 0.098 & 0.802 & & & \\
\hline Phosphate, mg/dL & -0.136 & 0.291 & & & \\
\hline Glucose, mg/dL & 0.001 & 0.835 & & & \\
\hline Total cholesterol, mg/dL & -0.0001 & 0.969 & & & \\
\hline Triglyceride, mg/dL & 0.003 & 0.209 & & & \\
\hline $\mathrm{LDL}-\mathrm{C}, \mathrm{mg} / \mathrm{dL}$ & 0.005 & 0.390 & & & \\
\hline $\mathrm{HDL}-\mathrm{C}, \mathrm{mg} / \mathrm{dL}$ & -0.010 & 0.283 & & & \\
\hline Ln C-reactive protein, mg/dL & -0.123 & 0.329 & & & \\
\hline Serum iron, $\mu \mathrm{g} / \mathrm{dL}$ & -0.004 & 0.539 & & & \\
\hline $\mathrm{TIBC}, \mu \mathrm{g} / \mathrm{dL}$ & -0.005 & 0.252 & & & \\
\hline TSAT, $\%$ & -0.004 & 0.813 & & & \\
\hline
\end{tabular}


Table 3 Univariable and multivariable regression analysis for $\mathrm{Hb}$ levels (Continued)

\begin{tabular}{|c|c|c|c|c|c|}
\hline Ln ferritin, ng/dL & -0.569 & 0.009 & -0.276 & -0.177 & 0.221 \\
\hline Ln whole PTH, pg/mL & -0.018 & 0.924 & & & \\
\hline Ln BNP, pg/mL & -0.216 & 0.021 & -0.146 & -0.220 & 0.233 \\
\hline Ln eEPO, U/mL & -0.042 & 0.897 & -0.046 & -0.021 & 0.884 \\
\hline Ln BMG, mg/L & -0.545 & 0.200 & & & \\
\hline $\mathrm{HbA} 1 \mathrm{c}, \%$ & 0.098 & 0.649 & & & \\
\hline Use of RAS inhibitors & 1.248 & 0.116 & & & \\
\hline Use of calcium channel blockers & -0.431 & 0.227 & & & \\
\hline Use of $\beta$ blockers & -0.153 & 0.629 & & & \\
\hline Use of calcium-containing PBs & -0.135 & 0.780 & & & \\
\hline Use of non-calcium-containing PBs & -0.145 & 0.650 & & & \\
\hline Use of iron preparations & 0.044 & 0.908 & & & \\
\hline Use of vitamin $D$ & -0.108 & 0.733 & & & \\
\hline Use of cinacalcet hydrochloride & 0.175 & 0.764 & & & \\
\hline
\end{tabular}

Variables with a $P$ value of $<0.05$ in the univariable analysis were included in addition to CTR, ESA dose, and log-transformed eEPO in the multivariable analyses. Renal Kt $/ \mathrm{V}$, renal $\mathrm{Ccr}$, and urine volume were excluded from multivariable analysis because of their multicollinearity with mean rCUC. The values written in Italic letter show significant association with $\mathrm{Hb}$ levels. A $P$ value of $<0.05$ was considered statistically significant

Abbreviations: $A P D$ automated peritoneal dialysis, $B M G \beta_{2}$-microglobulin, $B N P$ brain natriuretic peptide, $C T R$ cardiothoracic ratio, $C c r$ creatinine clearance, $D N$ diabetic nephropathy, $D / P c r$ dialysate-to-plasma creatinine ratio, eEPO endogenous erythropoietin, ESA erythropoiesis-stimulating agent, $H b$ hemoglobin, $H b A 1 c$ hemoglobin $A 1 \mathrm{C}$, $H D L-C$ high-density lipoprotein cholesterol, HG high-glucose (2.5\%), Kt/V urea clearance, LDL-C low-density lipoprotein cholesterol, Ln log-transformed, PBs phosphate binders, PTH parathyroid hormone, RAS renin-angiotensin system, $r C U C$ renal creatinine and urea clearance, TIBC total iron binding capacity, TSAT transferrin saturation

demonstrated that indoxyl sulfate treatment suppressed EPO mRNA expression and decreased the nuclear accumulation of hypoxia-inducible factor- $\alpha$ proteins and hypoxia-responsive element-luciferase activity following hypoxia. This suggested a potential connection between a uremic toxin and the desensitization of the oxygen-sensing mechanism in EPO-producing cells, which may explain anemia in CKD patients. However, these mechanisms are mediated by decreased eEPO production and do not explain the lack of a relationship between eEPO concentration and $\mathrm{Hb}$ levels observed in the present study.

More recently, two observational reports on anemia in PD patients have been published [22, 23]. Huang et al. [22] reported that serum indoxyl sulfate was negatively correlated with $\mathrm{Hb}$ level in 90 non-anuric PD patients but did not show the association of $\mathrm{Kt} / \mathrm{V}$ and $\mathrm{Hb}$ levels. Meanwhile, Ryta et al. [23] reported the association of total $\mathrm{Kt} / \mathrm{V}$ with $\mathrm{Hb}$ levels both in 2180 prevalent and 88 incident PD patients. However, this report unfortunately did not show the association of renal $\mathrm{Kt} / \mathrm{V}$ and $\mathrm{Hb}$ level. The findings of the two reports are slightly different from the present study but support our speculation that accumulation of uremic toxins may be involved in anemia in PD patients.

While several studies have reported the role of iron metabolism, renin-angiotensin system inhibitors, BMG levels, serum albumin levels, parathyroid hormone, Creactive protein, and other factors in anemia management
[24-26], we did not find any correlations of these factors in the present study.

Distribution of original disease was different among three tertiles; that is, prevalence of DN increased with a decrease in mean rCUC, although not significant. To date, there have been a few reports on the association between $\mathrm{Hb}$ levels and diabetes, in which diabetic patients were reported to require less ESA than non-diabetic patients [27], whereas no association was reported between diabetes and anemia [28]. In our study, no significant association was observed between $\mathrm{DN}$ and $\mathrm{Hb}$ levels in the univariable analysis, and the association between mean rCUC and $\mathrm{Hb}$ level was robust even when the variable "diabetic nephropathy" was added to the multivariable model. Thus, we consider that this bias would not affect this association.

This study had some limitations. It had a cross-sectional design, which limited the interpretation of the results with respect to cause and effect. Another limitation is the small number of subjects included in our study. Moreover, we could not identify the uremic toxin that might inhibit erythropoiesis or shorten the red blood cell life span. Nevertheless, there are some strengths in this study that eEPO concentration was measured and the involvement of eEPO concentration was examined in the association between RKF and $\mathrm{Hb}$ level. To the best of our knowledge, this study is the first report which focused on these associations. 


\section{Conclusion}

The findings in the present study demonstrated that a decline in RKF is associated with a low $\mathrm{Hb}$ level independent of ESA dose and eEPO concentration. This suggests the existence of a uremic toxin as an inducer of anemia, which is probably eliminated mainly by RKF, but not by PD. Further research is needed to clarify the specific mechanism responsible for anemia in PD patients.

\section{Additional file}

Additional file 1: Table S1. Univariable and multivariable regression analysis for Hb levels. (DOCX 33 kb)

\section{Acknowledgements}

We thank the investigators and the doctors who participated in the present study. We thank Edanz Editing (http://www.edanzediting.co.jp/) for carefully reading and preparing our manuscript.

\section{Funding}

None to declare.

\section{Availability of data and materials}

Data share is not allowed by our institutional review board.

\section{Authors' contributions}

KaT and KuT contributed to the research idea and study design. KaT, KuT, HY, SY, ST, AT, ME, KF, and KM carried out the data acquisition. KUT and HY participated in the data cleaning. KaT and KuT interpreted the data. KaT and HY participated in the statistical analysis. TK carried out the supervision. Each author contributed important intellectual content during manuscript drafting or revision and accepts accountability for the overall work by ensuring that questions pertaining to the accuracy or integrity of any portion of the work are appropriately investigated and resolved. KaT takes responsibility that this study has been reported honestly, accurately, and transparently; that no important aspects of the study have been omitted; and that any discrepancies from the study as planned have been explained. All authors read and approved the final manuscript.

\section{Ethics approval and consent to participate}

All procedures performed in studies involving human participants were in accordance with the ethical standards of the institutional research committee at which the studies were conducted (approval number of the Ethics Committee of Kyushu University Hospital: 26-223) and with the 1964 Helsinki declaration and its later amendments or comparable ethical standards. This study is a subanalysis of our multicenter cohort study (Fukuoka Peritoneal Dialysis Database Study), which was registered in the University Hospital Medical Information Network (UMIN) clinical trial registry (UMIN000018902).

\section{Consent for publication}

Not applicable.

\section{Competing interests}

The authors declare that they have no competing interests.

\section{Publisher's Note}

Springer Nature remains neutral with regard to jurisdictional claims in published maps and institutional affiliations.

\section{Author details}

${ }^{1}$ Department of Integrated Therapy for Chronic Kidney Disease, Graduate School of Medical Sciences, Kyushu University, 3-1-1 Maidashi, Higashi-ku, Fukuoka 812-8582, Japan. ²Department of Medicine and Clinical Science, Graduate School of Medical Sciences, Kyushu University, Fukuoka, Japan.

${ }^{3}$ Clinical Research Center, Saga University Hospital, Saga, Japan.
Received: 6 April 2017 Accepted: 14 August 2017

Published online: 09 November 2017

\section{References}

1. Besarab A, Bolton WK, Browne JK, Egrie JC, Nissenson AR, Okamoto DM, et al. The effects of normal as compared with low hematocrit values in patients with cardiac disease who are receiving hemodialysis and epoetin. N Engl J Med. 1998;339:584-90.

2. Drueke TB, Locatelli F, Clyne N, Eckardt KU, Macdougall IC, Tsakiris D, et al. Normalization of hemoglobin level in patients with chronic kidney disease and anemia. N Engl J Med. 2006:355:2071-84.

3. Singh AK, Szczech L, Tang KL, Barnhart H, Sapp S, Wolfson M, et al. Correction of anemia with epoetin alfa in chronic kidney disease. N Engl J Med. 2006;355:2085-98.

4. Pfeffer MA, Burdmann EA, Chen CY, Cooper ME, de Zeeuw D, Eckardt KU, et al. A trial of darbepoetin alfa in type 2 diabetes and chronic kidney disease. N Engl J Med. 2009;361:2019-32.

5. Wang AY, Lai KN. The importance of residual renal function in dialysis patients. Kidney Int. 2006;69:1726-32.

6. Marron B, Remon C, Perez-Fontan M, Quiros P, Ortiz A. Benefits of preserving residual renal function in peritoneal dialysis. Kidney Int Suppl. 2008:108:S42-51.

7. Perl J, Bargman JM. The importance of residual kidney function for patients on dialysis: a critical review. Am J Kidney Dis. 2009:53:1068-81.

8. Wang AY, Brimble KS, Brunier G, Holt SG, Jha V, Johnson DW, et al. ISPD cardiovascular and metabolic guidelines in adult peritoneal dialysis patients part I-assessment and management of various cardiovascular risk factors. Perit Dial Int. 2015;35:379-87.

9. Lopez-Menchero R, Miguel A, Garcia-Ramon R, Perez-Contreras J, Girbes V. Importance of residual renal function in continuous ambulatory peritoneal dialysis: its influence on different parameters of renal replacement treatment. Nephron. 1999:83:219-25.

10. Penne EL, van der Weerd NC, Grooteman MP, Mazairac AH, van den Dorpel MA, Nube MJ, et al. Role of residual renal function in phosphate control and anemia management in chronic hemodialysis patients. Clin J Am Soc Nephrol. 2011;6:281-9.

11. Yamada S, Tsuruya K, Taniguchi M, Yoshida H, Tokumoto M, Hasegawa S, et al. Relationship between residual renal function and serum fibroblast growth factor 23 in patients on peritoneal dialysis. Ther Apher Dial. 2014;18:383-90.

12. Working Group Committee for Preparation of Guidelines for Peritoneal Dialysis, Japanese Society for Dialysis Therapy. 2009 Japanese Society for Dialysis Therapy guidelines for peritoneal dialysis. Ther Apher Dial. 2010;14:489-504.

13. KDOQI, National Kidney Foundation. KDOQI clinical practice guidelines and clinical practice recommendations for anemia in chronic kidney disease. Am J Kidney Dis. 2006:47:S11-145.

14. Tsubakihara Y, Nishi S, Akiba T, Hirakata H, Iseki K, Kubota M, et al. 2008 Japanese Society for Dialysis Therapy: guidelines for renal anemia in chronic kidney disease. Ther Apher Dial. 2010;14:240-75.

15. Hume R, Weyers E. Relationship between total body water and surface area in normal and obese subjects. J Clin Pathol. 1971:24:234-8.

16. Ifudu O, Feldman J, Friedman EA. The intensity of hemodialysis and the response to erythropoietin in patients with end-stage renal disease. N Engl Med. 1996;334:420-5.

17. Matsuo N, Yokoyama K, Maruyama Y, Ueda Y, Yoshida H, Tanno Y, et al. Clinical impact of a combined therapy of peritoneal dialysis and hemodialysis. Clin Nephrol. 2010;74:209-16.

18. Evenepoel P, Bammens B, Verbeke K, Vanrenterghem Y. Superior dialytic clearance of beta(2)-microglobulin and p-cresol by high-flux hemodialysis as compared to peritoneal dialysis. Kidney Int. 2006:70:794-9.

19. Pawlak D, Koda M, Pawlak S, Wolczynski S, Buczko W. Contribution of quinolinic acid in the development of anemia in renal insufficiency. Am J Physiol Renal Physiol. 2003;284:F693-700.

20. Schwarcz R, Whetsell WO Jr, Mangano RM. Quinolinic acid: an endogenous metabolite that produces axon-sparing lesions in rat brain. Science. 1983;219:316-8.

21. Chiang CK, Tanaka T, Inagi R, Fujita T, Nangaku M. Indoxyl sulfate, a representative uremic toxin, suppresses erythropoietin production in a HIF-dependent manner. Lab Investig. 2011:91:1564-71.

22. Huang JY, Hsu CW, Yang CW, Hung CC, Huang WH. Role of anuria in the relationship between indoxyl sulfate and anemia in peritoneal dialysis patients. Ther Clin Risk Manag. 2016;12:1797-803. 
23. Ryta A, Chmielewski M, Debska-Slizien A, Jagodzinski P, Sikorska-Wisniewska M, Lichodziejewska-Niemierko M. Impact of gender and dialysis adequacy on anaemia in peritoneal dialysis. Int Urol Nephrol. 2017:49:903-8.

24. Tonelli M, Blake PG, Muirhead N. Predictors of erythropoietin responsiveness in chronic hemodialysis patients. ASAIO J. 2001;47:82-5.

25. Nakamoto H, Kanno Y, Okada H, Suzuki H. Erythropoietin resistance in patients on continuous ambulatory peritoneal dialysis. Adv Perit Dial. 2004;20:111-6.

26. Pajek J, Bucar-Pajek M, Grego K, Gucek A, Bevc S, Ekart R, et al. Epoetin responsiveness in peritoneal dialysis patients: a multi-center Slovenian study. Ther Apher Dial. 2005;9:228-32.

27. Mitwalli A, Alsuwaida A, Wakeel JA, Usama S, Zainalddain N, Al Ghonaim M, et al. Do diabetic dialysis patients require more or less of erythropoietin? Ann Saudi Med. 2013;33:457-63.

28. Oliveira MC, Ammirati AL, Andreolli MC, Nadalleto MA, Barros CB, Canziani ME. Anemia in patients undergoing ambulatory peritoneal dialysis: prevalence and associated factors. J Bras Nefrol. 2016;38:76-81.

Submit your next manuscript to BioMed Central and we will help you at every step:

- We accept pre-submission inquiries

- Our selector tool helps you to find the most relevant journal

- We provide round the clock customer support

- Convenient online submission

- Thorough peer review

- Inclusion in PubMed and all major indexing services

- Maximum visibility for your research

Submit your manuscript at www.biomedcentral.com/submit
Biomed Central 